\title{
Studying the Polymerization of Aniline on Fullerene
}

\author{
Hanan Elhaes, ${ }^{1, *}$, Afaf Babaier ${ }^{2}$ and Mohamed Abd El-Aal ${ }^{3,4}$ \\ ${ }^{1}$ Physics Department, Faculty of Women for Arts, Science, and Education, Ain Shams University, 11757 Cairo, Egypt \\ ${ }^{2}$ Physics Department, Faculty of Science-Jazan University, 2097 Jazan, Kingdom of Saudi Arabia, KSA \\ ${ }^{3}$ Spectroscopy Department, National Research Centre, 12311, Dokki, Cairo, Egypt \\ ${ }^{4}$ Physics Department, Faculty of Science, Taif University, Saudi Arabia
}

\begin{abstract}
Polyaniline is among a family of conductive polymers, that exhibits properties similar to some metals. Accordingly quantum mechanical calculations have been performed to study the possible polymerization of aniline on the surface of fullerene. Several model molecules representing the polymerization of aniline are studied; polymerization is tested with fullerene and fulleropyrrolidine surfaces. Total dipole moment, ionization potential, molecular weight, molecular dimension and molecular point group for $\mathrm{C}_{60}$-aniline and $\mathrm{C}_{60}$ - pyrrolidine-aniline have been computed with the semiempirical PM3 method. The molecular point group has changed into $\mathrm{C} 1$ point group corresponding to $\mathrm{C}_{60}$-aniline and $\mathrm{C}_{60^{-}}$pyrrolidine-aniline, which reflects a change in the symmetry. Results indicate also that polarization increases the calculated total dipole moment, molecular weight and molecular dimension while ionization potential has slightly decreased. Final heat of formation increases with temperature for both $\mathrm{C}_{60}$-aniline and $\mathrm{C}_{60}$-pyrrolidine aniline. This reflects the thermal stability of the polymerized aniline on both fullerene and fulleropyrrolidine. Calculated HOMO-LUMO energy indicate that polyaniline which polymerizes on fullerene is the most probable.
\end{abstract}

Keywords: Molecular modeling, Semiempirical calculations. Fullerenes, Fulleropyrrolidine and Polyaniline.

\section{INTRODUCTION}

Fullerene derivatives were the subject of intensive studies, where a wide variety of those derivatives have been prepared and used in various physical, biological and pharmacological fields [1-4]. Fulleropyrrolidines are among the most studied fullerene derivatives which have been used for numerous biological applications [5, 6]. Polyaniline uniqueness among the class of conducting polymers is based on its wide range of electrical, electrochemical, electroluminescence, optical and anticorrosion applications. It is characterized also by its good stability [7-10]. Polyaniline is typically synthesized by the oxidation of aniline monomer either electrochemically [11]; or chemically [12-14]. Aniline forms complexes with transition metal ions in the clay minerals interlayer by the coordination of free electron like montmorillonite pair of the amino group to the metal ions $[15,16]$. Car-Parrinello ab initio molecular dynamics MD, was used to investigate polyaniline geometries [17]. Furthermore, the polaron lattice and the mechanism of conduction for doped polyaniline were studied by ab initio MO calculations [18]. A scaled quantum mechanical oligomer force field for oligomers of leucoemeraldine base and for one oligomer of the imine form of polyaniline was established [19]. Both vibra-

*Address correspondence to this author at the Physics Department, Faculty of Women for Arts, Science, and Education, Ain Shams University, 11757 Cairo, Egypt; Tel: 00201283135136; E-mails: medahmed@yahoo.com, medahmed@hotmail.com tional spectroscopy and ab initio calculations were used to study the adsorption and polymerization of aniline on $\mathrm{Cu}(\mathrm{II})$ montmorillonite [20]. Further vibrational assignment for polyaniline emeraldine base was achieved with FTIR; semiempirical; HF and DFT calculations [21]. Recently polyaniline/silica gel composites were prepared by in situ fast polymerization method. The structural characteristics, morphological information of as-prepared polymers were discussed [22]. A study was carried out on the biocompatibility of polyaniline and polyaniline silver coated polyurethane composite. It is stated that, coating polyurethane with polyaniline and polyaniline silver renders the surface conductive [23]. Glucose oxidase (GOx) was self-encapsulated within polyaniline and polypyrrole. Applicability of enzymatically synthesized polyaniline and polypyrrole was evaluated [24]. Recently it is also found that, polyaniline after doping with heavy metals like $\mathrm{Cu}$ and $\mathrm{Zn}$ furnish as a good surface for adsorption process. Accordingly the adsorption behaviors of Sodium Dodecyl Benzene Sulfonate onto polyaniline were studied [25].

This work has been conducted to study the possible polymerization of aniline on the surface of fullerenes. First the polymerization was tried onto the surface directly; then another attempt was made to perform polymerization through pyrrolidine ring attached with fullerene surface. Semiempirical quantum mechanical calculations were utilized to verify this assumption. For comparison B3LYP/6-31 $\mathrm{g} * *$ as well as experimental results are utilized. 


\section{MATERIAL AND METHODS}

\subsection{Polymerization of Aniline}

For comparison purpose aniline is prepared by adsorption upon $\mathrm{Cu}(\mathrm{II})$-montmorillonite $[20,21]$. Batch adsorption experiments in the presence of oxygen were performed to study the interlayer reactions of aniline on $\mathrm{Cu}$ (II)-montmorillonite in aqueous solutions. At concentrations below a critical value of $\mathrm{CC}=2.6 \mathrm{mmol} \mathrm{dm}{ }^{-3}$ only a coloured $\mathrm{Cu}$ (II)-aniline complex is formed, characterized by a stability constant of $\log ($ Kass $/ \mathrm{dm} 3 \mathrm{~mol}-1)=1.5$. At concentrations beyond CC aniline polymerizes yielding a dark brown product.

\subsection{Calculation Details}

In order to build the model molecules aniline monomer is attached to fullerene; fulleropyrrolidine surface respectively. Aniline is further attached with other aniline up to 4 units through hydrogen bonding. Accordingly 8 model molecules are constructed in addition to aniline; fullerene and fulleropyrrolidine.

Calculations were carried out on a personal computer. The geometry of the polymerization of aniline upon the surface of fullerene and fulleropyrrolidine were optimized by performing PM3 semiempirical quantum mechanics calculation using a MOPAC 2002 package which was implemented within the CAChe Program [26]. Some physical parameters like total dipole moment; ionization potential and HOMOLUMO energies were calculated at the same level of theory. For comparison polyaniline is re-calculated using the Gaus- sian 03 program system [27]. Geometries were optimized using density functional theory DFT, hybrid Becke 3-LeeYang-Parr (B3LYP) exchange correlation functional [28-30] with $6-31 \mathrm{~g} * *$ basis set. Vibrational spectrum was calculated at the same level of theory.

\section{RESULTS AND DISCUSSION}

The polymerization of aniline in aqueous solution was already studied early on 1994 [31]. Tochima et al. found that, aniline is oxidized by oxygen and subsequently polymerizes radically. The polymerization process is carried out upon a surface which is tried in this work as fullerene. Aniline monomer is attached to fullerene surface close to carbon atom no $22\left(\mathrm{C}_{22}\right)$, then attached to other aniline units as dimmer, trimmer and emeraldine base (4 units). At each step the geometry is optimized then vibrational spectrum is calculated to ensure that the obtained structure is real and not a transition state ones. Another attempt was tried via pyrrolidine ring in order to check the possible polymerization of aniline upon fulleropyrrolidine. The change in geometrical; physical and vibrational characteristics will be followed through $\mathrm{C}_{22}$ as well as its surrounding atoms. Fig. (1) presents the general formular structure for fullerene; fulleropyrrolidine, and the base form of polyaniline emeraldin base.

Table 1 represents the net charge distribution for $\mathrm{C}_{60}-$ aniline and $\mathrm{C}_{60^{-}}$pyrrolidine -aniline in the position of $\mathrm{C}_{22}$ and $\mathrm{C}_{55}$. As seen from the table the charge increases by the polymerization of aniline upon the surface of fullerene and fulleropyrrolidine. Table 2 presents some important physical
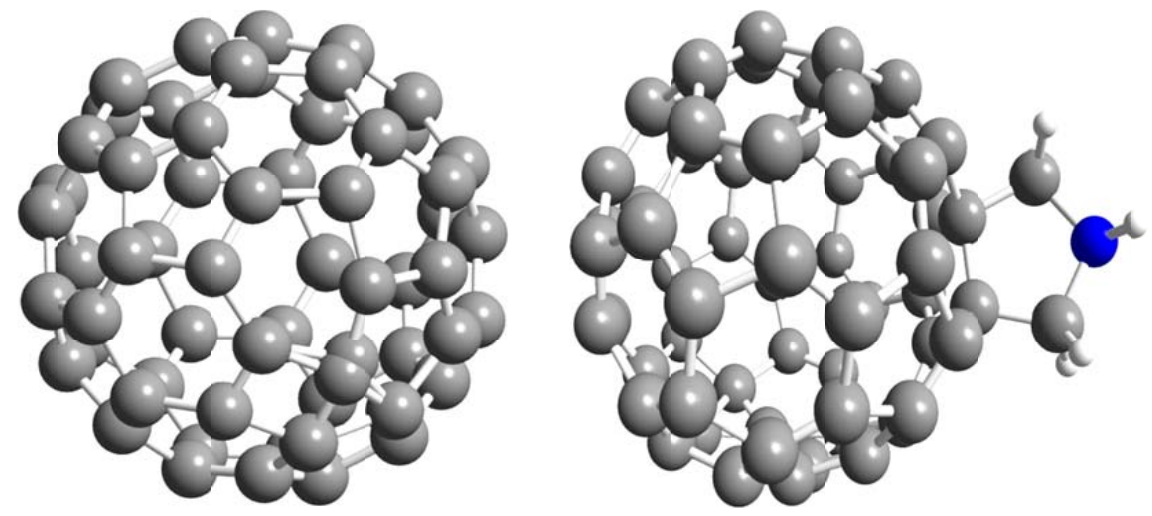

a- Fullerene

b- Fulleropyrrolidine

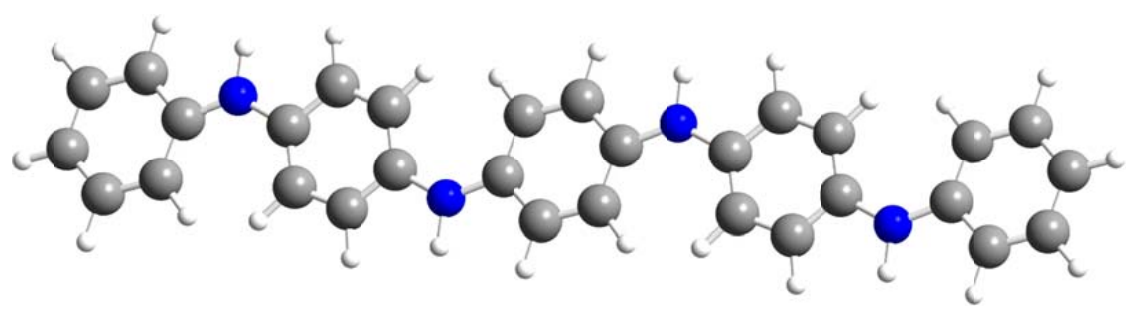

c Polyaniline.

Fig. (1). General formular for a- fullerene; b- fulleropyrrolidine, $\mathbf{c}-$ the base form of polyaniline emeraldin base and their calculated structures. 


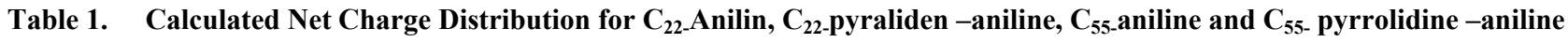

\begin{tabular}{|c|c|c|c|c|}
\hline & C & N.E & s-Pop & p-Pop \\
\hline $\mathrm{C} 22$ & 0.000009 & 4.0000 & 1.16982 & 2.83019 \\
\hline C22-dimer & 0.155350 & 3.8447 & 1.17143 & 2.67322 \\
\hline C22-trimer & 0.189514 & 3.8105 & 1.16317 & 2.64732 \\
\hline C22-Pyr & 0.063423 & 4.0634 & 1.19415 & 2.86928 \\
\hline C22pyr-monomer & 0.060377 & 3.9396 & 1.17523 & 2.76439 \\
\hline C22pyr-dimer & 0.060464 & 3.9395 & 1.17511 & 2.76443 \\
\hline C22pyr-trimer & 0.059793 & 3.9402 & 1.17550 & 2.76471 \\
\hline C55-monomer & 0.130657 & 3.8693 & 1.15888 & 2.71046 \\
\hline C55-dimer & 0.131780 & 3.8682 & 1.16411 & 2.70411 \\
\hline C55-trimer & 0.191696 & 3.8083 & 1.15557 & 2.65274 \\
\hline C55-poly & 0.140427 & 3.8596 & 1.16271 & 2.69686 \\
\hline C55-Pyr & 0.024237 & 4.0242 & 1.18659 & 2.83765 \\
\hline C-55pyr-monomer & 0.060717 & 3.9393 & 1.17528 & 2.76400 \\
\hline C-55pyr-dimer & 0.061387 & 3.9386 & 1.17521 & 2.76341 \\
\hline
\end{tabular}

parameters which were calculated with PM3. As seen in Table 2 the molecular weight of optimized $\mathrm{C}_{60}$ is 720.660 increased ongoing from $\mathrm{C}_{60}$-monomer towards $\mathrm{C}_{60}$ - polyaniline. In the case of $\mathrm{C}_{60}$-pyrrolidine-aniline the molecular weight is also increasing from $\mathrm{C}_{60}$ - pyrrolidine - monomer to $\mathrm{C}_{60}$ - pyrrolidine - polyaniline but it is higher than $\mathrm{C}_{60}$ aniline. The molecular dimension is slightly increasing from $7.09226 \AA$ in case of $\mathrm{C}_{60}$ to $9.89354 \AA$ in case of $\mathrm{C}_{60}$ - pyrrolidine. In both cases, $\mathrm{C}_{60}$ and $\mathrm{C}_{60}$ - pyrrolidine, the molecular dimension has increased by going from aniline monomer to polyaniline and is still higher in the case of $\mathrm{C}_{60}-$ pyrrolidine - aniline.

The molecular point group has changed from $\mathrm{Ih}$ to $\mathrm{C} 1$ point group corresponding to $\mathrm{C}_{60}$-aniline. A decrease in ionization potential goes from $\mathrm{C}_{60}$-aniline monomer toward $\mathrm{C}_{60}$ -polyaniline. The same behavior has been observed in the case of $\mathrm{C}_{60}$ - pyrrolidine -aniline. The total dipole moment has increased from 0.000 to 2.710 debeye corresponding to $\mathrm{C}_{60}$-pyrrolidine. The possible change in the partial charge distribution leads to an increase in the total dipole moment of $\mathrm{C}_{60}$-aniline and $\mathrm{C}_{60}$ - pyrrolidine -aniline by going from $\mathrm{C}_{60}$ -aniline monomer towards $\mathrm{C}_{60}$ - polyaniline and from $\mathrm{C}_{60}$ pyrrolidine -aniline monomer towards $\mathrm{C}_{60}-$ pyrrolidine polyaniline.
Table 3 represents the calculated, final heat of formation $(\mathrm{HF})$, enthalpy (En), heat capacity (HC), entropy (Et), free energy $(\mathrm{FE})$ and band gap energy $(\Delta \mathrm{E})$ at $298 \mathrm{k}$ using PM3 method. Band gap energy $(\Delta \mathrm{E})$ is calculated as the difference between highest occupied molecular orbital HOMO; and lowest unoccupied molecular orbital LUMO. From the table it is clear that $\Delta \mathrm{E}$ decreases by increasing the polymerization of $\mathrm{C}_{60}$-aniline and $\mathrm{C}_{60}$ - pyrrolidine - aniline. Adding the pyrrolidine to $\mathrm{C}_{60}$ decreases the value of the band gap energy. Final heat of formation of $\mathrm{C}_{60}$ has changed from 12434.0 to $799.62 \mathrm{Kcal} / \mathrm{mol}$ by adding the pyrrolidine. Final heat of formation deceases from $12434.0 \mathrm{Kcal} / \mathrm{mol}$ corresponding to $\mathrm{C}_{60}$ to $835.150 \mathrm{Kcal} / \mathrm{mol}$ which corresponds to $\mathrm{C}_{60^{-}}$ monomer. Heat of formation increases by going from $\mathrm{C}_{60^{-}}$ monomer to $\mathrm{C}_{60^{-}}$polyaniline in both cases of $\mathrm{C}_{60}$ - aniline and of $\mathrm{C}_{60}-$ pyr- aniline. Enthalpy increases from 104.8 $\mathrm{cal} / \mathrm{mol}$ corresponding to $\mathrm{C}_{60}$ to $14440.811 \mathrm{cal} / \mathrm{mol}$ corresponding to $\mathrm{C}_{60}-$ pyr. Enthalpy increases by going from $\mathrm{C}_{60^{-}}$ monomer to $\mathrm{C}_{60}$-polyaniline but it has higher value in the case of $\mathrm{C}_{60}-$ pyr- aniline compared to $\mathrm{C}_{60}$ - aniline. Heat capacity decreases from $124.7 \mathrm{cal} / \mathrm{mol} / \mathrm{Kelvin}$ in case of $\mathrm{C}_{60}$ to $118.485 \mathrm{cal} / \mathrm{mol} / \mathrm{k}$ for $\mathrm{C}_{60}-$ pyr. Heat capacity increases by going from $\mathrm{C}_{60}$-monomer to $\mathrm{C}_{60}$-polyaniline in both cases of $\mathrm{C}_{60}$ - aniline and of $\mathrm{C}_{60}-$ pyr- aniline and it has higher value in the case of $\mathrm{C}_{60}-$ pyr- aniline than $\mathrm{C}_{60}$ - aniline. En- 
Table 2. Calculated, Total Dipole Moment (TDM) as Debeye; Ionization Potential (IP) as eV; Molecular Weight (MW) Molecular Dimensional (MD) as Á and Molecular Point Group (MPG) for $\mathrm{C}_{60}$-aniline and $\mathrm{C}_{60}$ - pyrrolidine -aniline

\begin{tabular}{|c|c|c|c|c|c|}
\hline & TDM & IP & MW & MD & MPG \\
\hline $\mathrm{C}_{60}$ & 0.00 & 9.48189 & 720.660 & 7.09226 & Ih \\
\hline $\mathrm{C}_{60}$-monomer & 2.315 & 8.76369 & 787.750 & 10.93786 & $\mathrm{C} 1$ \\
\hline $\mathrm{C}_{60}$-dimer & 5.151 & 8.03331 & 878.862 & 11.60551 & $\mathrm{C} 1$ \\
\hline $\mathrm{C}_{60}$-trimer & 13.990 & 7.18361 & 969.975 & 14.27213 & $\mathrm{C} 1$ \\
\hline $\mathrm{C}_{60}$-poly & 12.058 & 6.97516 & 1061.087 & 14.65865 & $\mathrm{C} 1$ \\
\hline $\mathrm{C}_{60}-\mathrm{Pyr}$ & 2.710 & 8.91921 & 763.728 & 9.89354 & $\mathrm{C} 1$ \\
\hline $\mathrm{C}_{60}$-pyr-monomer & 1.764 & 8.79927 & 839.826 & 14.83739 & $\mathrm{C} 1$ \\
\hline $\mathrm{C}_{60}$-pyr-dimer & 1.813 & 8.32169 & 930.938 & 19.22302 & $\mathrm{C} 1$ \\
\hline $\mathrm{C}_{60}$-pyr-trimer & 2.332 & 8.21727 & 1022.050 & 21.20113 & $\mathrm{C} 1$ \\
\hline $\mathrm{C}_{60}$ pyr-poly & 3.211 & 8.00945 & 1113.162 & 20.47864 & $\mathrm{C} 1$ \\
\hline
\end{tabular}

Table 3. Calculated, Heat of Formation (HF) as Kcal/mol, Enthalpy (En) as (cal/mol). Heat Capacity (HC) as (cal/mol/Kelvin), Entropy (Et) as (cal/mol/Kelvin), Free Energy (FE) as (Kcal/mol) and HOMO-LUMO Band Gap Energy $(\Delta E)$ as $(\mathrm{eV})$ at $298 \mathrm{k}$ Using PM3 Method at $298 \mathrm{k}$, for $\mathrm{C}_{60}$-aniline and $\mathrm{C}_{60^{-}}$pyrrolidine -aniline

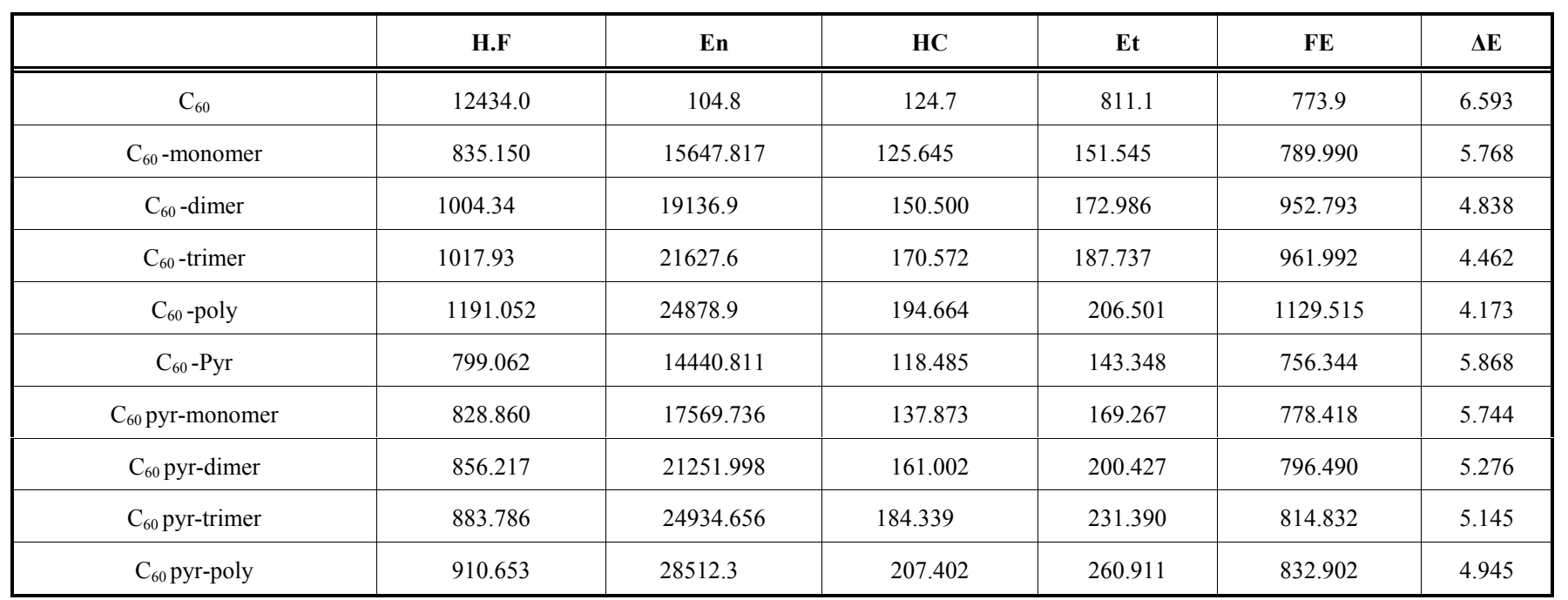

tropy decreases from $811.1 \mathrm{cal} / \mathrm{mol} / \mathrm{Kelvin}$ for $\mathrm{C}_{60}$ to 143.348 $\mathrm{cal} / \mathrm{mol} /$ Kelvin for $\mathrm{C}_{60}-$ pyr. Entropy increases by going from $\mathrm{C}_{60}$-monomer to $\mathrm{C}_{60}$-poly in both cases of $\mathrm{C}_{60}$-aniline and $\mathrm{C}_{60}-\mathrm{pyr}-$ aniline. However it has higher value in the case of $\mathrm{C}_{60}$ - pyr- aniline than $\mathrm{C}_{60}$ - aniline. Free energy increases by going from $\mathrm{C}_{60}$-monomer to $\mathrm{C}_{60}$-poly in both cases of $\mathrm{C}_{60}$-aniline and $\mathrm{C}_{60}-\mathrm{pyr}$ - aniline but it has lower value in the case of $\mathrm{C}_{60}-$ pyr- aniline than $\mathrm{C}_{60}$-aniline. Table 4 represents the calculated, heat of formation (HF) entropy (Et), enthalpy (En), heat capacity (HC) and free energy (FE) using PM3 method at different temperatures for $\mathrm{C}_{60}$ - pyr- polyaniline. From the table we notice that all these parameters increase with increasing temperature except for free energy which decreases with increasing temperature. Still the values of heat of formation, entropy, enthalpy, and heat capacity of $\mathrm{C}_{60}-$ pyr - aniline are higher than $\mathrm{C}_{60}-$ aniline but the opposite side saw for free energy. The same behaviour observed in the case of $\mathrm{C}_{60}$ - aniline as shown in Table 5.

The calculated vibrational spectra provide clear verification for the structural parameters. The calculated spectra of $\mathrm{C}_{60}$ - aniline as compared with $\mathrm{C}_{60}$ are shown in Fig. (2). The characteristic spectrum of $\mathrm{C}_{60}$ has been discussed in our previous work $[32,33]$. The spectrum of $\mathrm{C}_{60}$ shows sharp spectral bands as a result of the highly symmetric structure of $\mathrm{C}_{60}$. As a result of polymerization fullerenes showed the four characteristic bands remaining unchanged but broadened as a result of changing the molecular symmetry. The same behaviour is observed in the calculated spectra of $\mathrm{C}_{60}-\mathrm{pyr}$ - aniline as compared with $\mathrm{C}_{60}$ as seen in Fig. (3). In fact, the assignment of such structure needs higher level of theory. Polyaniline is calculated at B3LYP/6-31g $(\mathrm{d}, \mathrm{p})$. Table 6 presents the experimental vibrational spectrum of aniline in liquid phase. The spectrum of aniline can be assigned as: $\mathrm{NH}_{2}$ bending or scissors mode which is attributed to $1626 \mathrm{~cm}^{-1}$, 


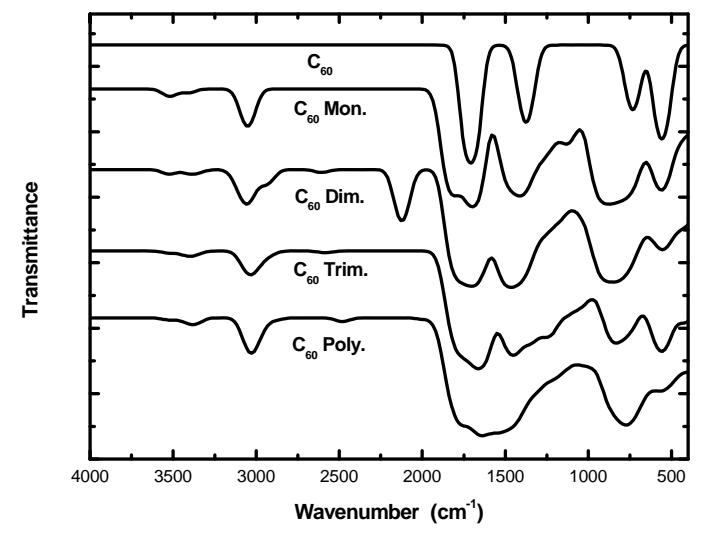

Fig. (2). PM3 calculated vibrational spectra for fullerene; fullerene- aniline monomer $\left(\mathrm{C}_{60}-\mathrm{Mon}\right)$; fullerene- aniline dimmer $\left(\mathrm{C}_{60}-\mathrm{Dim}\right)$; fullerene- aniline trimmer $\left(\mathrm{C}_{60}\right.$-Trim $)$ and fullerene- polyaniline $\left(\mathrm{C}_{60}\right.$-Poly $)$.

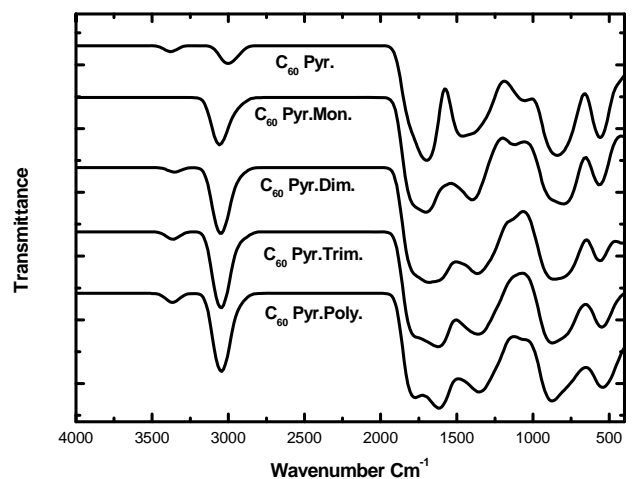

Fig. (3). PM3 calculated vibrational spectra for fulleropyrrolidine; fulleropyrrolidine - aniline monomer $\left(\mathrm{C}_{60}\right.$-Pyr.Mon ); fulleropyrrolidine aniline dimmer $\left(\mathrm{C}_{60}\right.$-Pyr.Dim $)$; fulleropyrrolidine - aniline trimmer $\left(\mathrm{C}_{60}\right.$-Pyr.Trim $)$ and fulleropyrrolidine - polyaniline $\left(\mathrm{C}_{60}-\mathrm{Pyr}\right.$. Poly $)$.

Table 4. Calculated, Heat of Formation (HF) as Kcal/mol, Enthalpy (En) as (cal/mol), Heat Capacity (HC) as (cal/mol/Kelvin), Entropy (Et) as (cal/mol/Kelvin), Free Energy (FE) as (Kcal/mol) and HOMO-LUMO Band Gap Energy ( $\Delta E)$ as (eV) Using PM3 Method at Different Temperature for $\mathrm{C}_{60}$ - pyrrolidine - polyaniline

\begin{tabular}{|c|c|c|c|c|c|}
\hline Temperature & HF & En & $\mathrm{HC}$ & Et & FE \\
\hline 250.00 & 901.652 & 19511.466 & 167.531 & 228.079 & 844.632 \\
\hline 300.00 & 911.069 & 28928.845 & 209.045 & 262.304 & 832.378 \\
\hline 400.000 & 935.945 & 53804.735 & 286.866 & 333.330 & 802.613 \\
\hline 450.000 & 951.170 & 69029.113 & 321.585 & 369.153 & 785.051 \\
\hline 500.000 & 968.050 & 85909.881 & 353.111 & 404.695 & 765.702 \\
\hline
\end{tabular}

and a ring stretching with a contribution of the $\mathrm{NH}_{2}$ scissoring band at $1604 \mathrm{~cm}^{-1}$. A band at $1497 \mathrm{~cm}^{-1}$ is characterized as typical ring stretching. The mode at $1264 \mathrm{~cm}^{-1}$ is assigned as partly to $\mathrm{C}-\mathrm{N}$ stretching and partly to the ring stretching vibration. Comparing between both calculated and experimental frequencies indicates that results of $\mathrm{B} 3 \mathrm{LYP} / 6-$ $31 \mathrm{G}(\mathrm{d}, \mathrm{p})$ are in good agreement with the experimental one. The optimized calculated polyaniline at this level of theory is indicated in Fig. (1-c). PM3 vibrations are not as accurate as
B3LYP/6-31G(d,p) however but it gives satisfactory vibrational frequencies of the studied polyaniline.

\section{CONCLUSION}

It is worth to mention that fullerene can exist in both gaseous as well as solid phases. Fulleropyrrolidine could be found only in the liquid phase. Accordingly we try to test the polymerization of aniline in solid phase through fullerene and in liquid phase through fulleropyrrolidine. Fullerene as 
Table 5. Calculated, Heat of Formation (HF) as Kcal/mol, Enthalpy (En) as (cal/mol). Heat Capacity (HC) as (cal/mol/Kelvin), Entropy (Et) as (cal/mol/Kelvin), Free Energy (FE) as (Kcal/mol) and HOMO-LUMO Band Gap Energy ( $\Delta E)$ as (eV) Using PM3 Method at Different Temperature for $\mathrm{C}_{60}$ - polyaniline

\begin{tabular}{|c|c|c|c|c|c|}
\hline Temperature & HF & En & $\mathrm{HC}$ & Et & FE \\
\hline 298.00 & 1191.052 & 24878.917 & 194.664 & 206.501 & 1129.515 \\
\hline 250.00 & 1182.630 & 16456.358 & 156.081 & 175.782 & 1138.685 \\
\hline 300.00 & 1191.440 & 25269.824 & 196.242 & 207.808 & 1129.101 \\
\hline 400.000 & 1214.858 & 48684.518 & 270.323 & 274.657 & 1104.995 \\
\hline 450.000 & 1229.206 & 63032.027 & 303.059 & 308.417 & 1090.418 \\
\hline 500.000 & 1245.112 & 78938.201 & 332.670 & 341.907 & 1074.159 \\
\hline
\end{tabular}

Table 6. Comparison Between PM3 and B3LYP/6-31G(d,p) as Well as Experimental Vibrational Frequencies (cm ${ }^{-1}$ ) of Polyaniline

\begin{tabular}{|c|c|c|c|}
\hline PM3 & B3LYP/6-31G(d,p) & Exp. & Assignment \\
\hline \hline 1776 & 1627 & 1626 & NH $_{2}$ sciss, ring str \\
\hline 1678 & 1608 & 1604 & ring str., NH2 sciss, \\
\hline 1580 & 1503 & 1497 & C-H bend, ring str \\
\hline 1369 & 1271 & 1264 & C-N str., ring str \\
\hline 1239 & 1176 & 1175 & C-H bend \\
\hline 1170 & 1156 & 1153 & C-H bend, \\
\hline 1049 & 1020 & 1030 & ring def, \\
\hline 971 & 994 & & Ring breathing \\
\hline 643 & 800 & 792 & C-N str., ring str., \\
\hline
\end{tabular}

well as fulleropyrrolidine could be a good surface for the process of polymerization of aniline. The polymerized aniline is thermally stable in terms of the PM3 calculated parameters. The band gap energy based upon HOMO/LUMO indicate that lower energy was achieved in case of fullerene $(4.173 \mathrm{eV})$ while it was slightly higher for fulleropyrrolidine. $(4.945 \mathrm{eV})$. Supporting the assumption that fullerene in the solid phase is more likely to be used as a surface for polymerization of aniline.

Another confirmation obtained from the calculated total dipole moment points to the fact that; the higher dipole moment (12.059 debeye) of fullerene-polyaniline indicates that the fullerene surface became more reactive for further polymerization of aniline. Lower total dipole moment value (3.211 debeye) corresponds to fulleropyrrolidine-polyaniline, indicating that fulleropyrrolidine is becoming slightly more stable after polymerization of aniline and no further polymerization took place on its surface.

PM3 semiempirical calculation is not in a good agreement with experimental results due to the effect of electron correlation which is not included in the semiemperical method. But the calculations are considered satisfactory as it takes relatively short time. The calculated physical parameters and HOMO/LUMO energy are considered good indicator for a given interaction. Accordingly, from this study one can conclude that precise spectroscopic data could be achieved with DFT, while satisfactory physical parameters could be achieved with semiemperical calculations.

\section{ACKNOWLEDGEMENT}

Authors would like to express their thanks to Prof. Dr. M.A. Kamel, Physics Department, Faculty of Education, Ain Shams University, Roxy, Cairo, Egypt. For his assistance during carrying out the calculations.

\section{CONFLICT OF INTEREST}

The author(s) confirm that this article content has no conflicts of interest.

\section{REFERENCES}

[1] Martın N. New challenges in fullerene chemistry. Chem Commun 2006; 20: 2093-104. 
[2] Hirsch A, Brettreich M. Fullerenes: chemistry and reactions. Weinheim: Wiley-VCH 2005.

[3] Kanwal A, Paul S, Chhowalla M. Organic memory devices using $\mathrm{C}_{60}$ and insulating polymer. Mater Res Soc Symp Proc 2005; 830: D7.2.1.

[4] Hameed AJ. Computational note on substitution effects on the structural and electronic properties of 1-(para-substituted phenyl diazenyl)pyrrolidinofullerenes. J Mol Struct 2006; 766: 73-5.

[5] Da Ros T, Spalluto G, Prato M. Biological applications of fullerene derivatives: a brief overview. Croat Chem Acta 2001; 74: 743-55.

[6] Tagmatarchis N, Prato M. The addition of azomethine ylides to [60] fullerene leading to fulleropyrrolidines. Synlett 2003; 34: 76879.

[7] Liu G, Freund MS. New approach for the controlled cross-linking of polyaniline: synthesis and characterization. Macromolecules 1997; 30: 5660-5.

[8] Nalwa HS. Handbook of organic conductive molecules and polymers. Vol. 1-4. New York: Wiley 1997.

[9] Novak P, Muller K, Santhanam KSV, Haas O. Electrochemically active polymers for rechargeable batteries. Chem Rev 1997; 97: 207-81.

[10] Angelopoulos M, Dipietro R, Zheng WG, MacDiarmid AG, Epstein AJ. Effect of selected processing parameters on solution properties and morphology of Polyaniline and impact on conductivity. Synth Met 1997; 84: 35-9.

[11] Liu G, Freund MS. Nucleophilic substitution reactions of polyaniline with substituted benzenediazonium ions: a facile method for controlling the surface chemistry of conducting polymers. Chem Mater 1996; 8: 1164-6.

[12] Yang J, Zhu W, Hou J, Xu M, Wan M. Substituted polyanilinepolypropylene film composites: preparation and properties. Synth Met 1996; 80: 283-9.

[13] Chen $\mathrm{CH}$. Thermal and morphological studies of chemically prepared EB form polyaniline powder. J Appl Polym Sci 2003; 89: 2142-8.

[14] Vecino M, Gonzalez I, Munoz ME, Santamaria A, Ochoteco EM, Pomposo JA. Synthesis of polyaniline and application in the design of formulations of conductive paintspolymer. Polym Adv Technol 2004; 15: 560-3.

[15] Edward B, Roman P, Semion S, et al. Infrared optics applications of thin polyaniline emeraldine base films. Polym Synth Met 2004; 140: 49-52.

[16] Heller L, Yariv S. Sorption of some anilines by Mn-, Co-, Ni-, Cu-, Zn-, and Cd-montmorillonite. In: Heller L, Ed. Proc Int Clay Conf Tokyo, Vol. 1. Jerusalem: Israel Univ Press 1969; pp. 741-55.

[17] Brocks G, Kelly PJ. Structure and properties of polymers calculated by ab-initio molecular dynamics. Synth Met 1993; 55-57: 4243-8.

[18] Baird NC, Huizhong W. The polaron lattice and the mechanism of conduction for doped polyaniline. Chem Phys Lett 1993; 202: 5015 .
[19] Kertsz M, Choi CH, Hong SY. Conformational information from vibrational spectra of polyaniline. Synth Met 1997; 85: 1073-6.

[20] Ilic M, Koglin E, Pohlmeier A, Narres HD, Schwuger MJ. Adsorption and polymerization of aniline on $\mathrm{Cu}(\mathrm{II})$-montmorillonite: Vibrational spectroscopy and ab initio calculation. Langmuir 2000; 16: 8946-51.

[21] Ibrahim M, Koglin E. Spectroscopic study of polyaniline emeraldine base: Modelling approach. Acta Chim Slov 2005; 52(2): 159-63.

[22] Pan J, Yao H, Guan W, et al. Selective adsorption of 2, 6dichlorophenol by surface imprinted polymers using polyaniline/silica gel composites as functional support: Equilibrium, kinetics, thermodynamics modeling. Chem Eng J 2011; 172(2-3): 84755.

[23] Prabhakar PK, Raj S, Anuradha PR, Sawant SN, Doble M. Biocompatibility studies on polyaniline and polyaniline-silver nanoparticle coated polyurethane composite. Colloid Surf B Biointerface 2011; 86(1): 146-53.

[24] Kausaite-Minkstimiene A, Mazeiko V, Ramanaviciene A, Ramanavicius A. Evaluation of amperometric glucose biosensors based on glucose oxidase encapsulated within enzymatically synthesized polyaniline and polypyrrole. Sens Actuators B Chem 2011; 158(1): 278-85.

[25] Özdemir U, Özbay B, Veli S, Zor S. Modeling adsorption of Sodium Dodecyl Benzene Sulfonate (Sdbs) Onto Polyaniline (Pani) by using multi linear regression and artificial neural networks. Chem Eng J 2010, [Epub ahead of print].

[26] MOPAC. Version 2.5.3, J. J. P. Stewart, Fujitsu Limited, Tokyo, Japan 2002.

[27] Frisch J, Trucks GW, Schlegel HB, et al. Gaussian 3, Revision c. 02. Wallingford CT: Gaussian Inc. 2004.

[28] Becke AD. Density-functional thermochemistry. III. The role of exact exchange. J Chem Phys 1993; 98: 5648-52.

[29] Lee C, Yang W, Parr RG. Development of the Colle-Salvetti correlation -energy formula into a functional of the electron density. Phys Rev B 1988; 37(2): 785-9.

[30] Miehlich B, Savin A, Stoll H, Preuss H. Results obtained with the correlation energy density functionals of becke and Lee, Yang and Parr. Chem Phys Lett 1989; 157(3): 200-6.

[31] Toshima N, Yan H, Ishiwatari M. Catalytic polymerization of Aniline and its derivatives by using Copper(II) salts and oxygen. New type of polyaniline with branched structure. Bull Chem Soc Jpn 1994; 67: 1947-53.

[32] Ibrahim M, El-Haes H. Spectroscopic study of $\mathrm{C}_{60}$ and $\mathrm{C}_{80}$ and their epoxides. Chin J Phys 2005; 43: 915-23.

[33] Ibrahim M, ElHaes H, Jalbout AF. Semiempirical molecular modelling study of $\mathrm{C}_{60}$ doped with Silicon, Germanium and Aluminium. Chin J Phys 2006; 44: 432-9. 